\title{
$\kappa$-Opioid Receptor Agonists Modulate Visceral Nociception at a Novel, Peripheral Site of Action
}

\author{
S. K. Joshi, ${ }^{1}$ Xin Su, ${ }^{1}$ Frank Porreca, ${ }^{2}$ and G. F. Gebhart ${ }^{1}$ \\ ${ }^{1}$ Department of Pharmacology, College of Medicine, The University of lowa, lowa City, lowa 52242, and 2 Department of \\ Pharmacology, University of Arizona, Tucson, Arizona 85721
}

$\kappa$-opioid receptor agonists ( $\kappa$-ORAs) have been shown to modulate visceral nociception through an interaction with a peripheral, possibly novel, $\kappa$-opioid-like receptor. We used in the present experiments an antisense strategy to further explore the hypothesis that $\kappa$-ORA effects in the colon are produced at a site different from the cloned $\kappa$-opioid receptor (KOR). An antisense oligodeoxynucleotide (ODN) to the cloned rat KOR was administered intrathecally $(12.5 \mu \mathrm{g}$, twice daily for $4 \mathrm{~d})$ to specifically knock-down the cloned KOR. Efficacy of the KOR antisense ODN treatment was behaviorally evaluated by assessing the antinociceptive effects of peripherally administered $\kappa$ - (EMD 61,753 and $U$ 69,593), $\mu$ - (DAMGO) and $\delta$ - (deltorphin) ORAs in the formalin test. Intrathecal antisense, but not mismatch ODN blocked the actions of EMD 61,753 and $U 69,593$ without affecting the ac- tions of DAMGO or deltorphin; a complete recovery of antinociceptive actions of the $\kappa$-ORA EMD 61,753 was observed $10 \mathrm{~d}$ after the termination of antisense ODN treatment. In contrast, the ability of EMD 61,753 to dose-dependently attenuate responses of pelvic nerve afferent fibers to noxious colonic distension was unaffected in the same rats in which the antisense ODN effectively knocked-down the KOR as assessed in the formalin test. Additionally, Western blot analysis demonstrated a significant downregulation of KOR protein in the L4-S1 dorsal root ganglia of antisense, but not mismatch ODN-treated rats. The present results support the existence of a non- $\kappa$-opioid receptor site of action localized in the colon.

Key words: peripheral opioids; nociception; colorectal distension; formalin test; antisense; visceral pain
Effects of opioid receptor agonists (ORAs) are mediated by one of the three opioid receptors: $\mu, \delta$, or $\kappa$. Because of undesirable effects like respiratory depression, tolerance, constipation, and abuse potential associated with $\mu$-ORAs, there is considerable interest in developing therapeutically useful agonists at other opioid receptors. $\kappa$-ORAs exert potent visceral antinociceptive effects by acting at peripheral sites. $\kappa$-ORAs, but not $\mu$ - or $\delta$-ORAs, dose-dependently attenuate responses of decentralized pelvic nerve afferent fibers to noxious colonic as well as urinary bladder distension, providing evidence for a peripheral site of action for these agonists (Sengupta et al., 1996; Su et al., 1997a,b). In addition, $\kappa$-ORAs are effective when injected directly into a peripheral site (e.g., tail; Kolesnikov et al., 1996) or intracolonically (Su et al., 2000).

Although only one $\kappa$-opioid receptor (KOR 1 ) has been cloned and characterized from rat CNS (Minami et al., 1993), binding studies suggest the existence of at least four different KOR subtypes (Pasternak, 1993). The existence of multiple subtypes of KOR is further supported by data obtained in assays of cutaneous nociception (Zukin et al., 1988; Clark et al., 1989). We have previously reported that $\kappa$-ORAs inhibit the response of pelvic nerve afferent fibers to noxious colonic or bladder distension (Sengupta et al., 1996; Su et al., 1997a,b) as well as the pressor and visceromotor responses to colonic distension in awake, unrestrained rats (Burton and Gebhart, 1998). In all these experiments, naloxone partially antagonized the actions of the $\kappa$-ORAs tested, but two $\kappa$-receptor selective antagonists, nor-binaltorphimine (nor-BNI) and 2-(3,4-dichlorophenyl)- $N$-methyl- $N$-[(1S)-1-3isothiocyanatophenyl)-2-(1-pyrrolidinyl)-ethyl]acetamide (DIPPA), were ineffective. Furthermore, the mean effective doses for the receptor-selective $\kappa$-ORAs examined in the electrophysiological studies were virtually the same, ranging between 2 and $10 \mathrm{mg} / \mathrm{kg}$,

Received Jan. 4, 2000; revised May 9, 2000; accepted May 11, 2000.

This work was supported by National Institutes of Health Grant NS 19912. We thank Mike Burcham for preparation of the figures and Alex Eapen for help with the Western blot technique.

Correspondence should be addressed to S. K. Joshi, Department of Pharmacology, BSB, The University of Iowa, Iowa City, IA 52242. E-mail: shailen-joshi@uiowa.edu. Copyright (C) 2000 Society for Neuroscience $0270-6474 / 00 / 205874-06 \$ 15.00 / 0$ which is in contrast to 100 -fold differences reported in the literature for these same $\kappa$-ORAs in other models (Chang et al., 1984; Devlin and Shoemaker, 1990; Nock et al., 1990; Paul et al., 1990). These findings led us to speculate that the $\kappa$-ORAs tested modulate visceral nociception through an interaction with a peripheral, novel, site of action that is different from the cloned KOR.

Antisense oligodeoxynucleotides (ODNs) have proven to be a valuable tool to study the pharmacology of opioid receptors (Pasternak and Standifer, 1995). There is evidence that intrathecal administration of antisense ODNs can also cause a "knock-down" of peripheral opioid receptors, presumably by inhibiting the synthesis of receptors in the dorsal root ganglion (Bilsky et al., 1996; Khasar et al., 1996). In the present study, we have used antisense strategy to both assess the peripheral visceral antinociceptive role, if any, of the cloned KOR and further explore the hypothesis that the $\kappa$-OR A effects in the colon are produced at a site different from the cloned KOR.

Parts of this paper have been published previously in abstract form (Joshi et al., 1999).

\section{MATERIALS AND METHODS}

Animals. Male Sprague Dawley rats (Harlan, Indianapolis, IN) were housed one or two per cage with ad libitum access to food and water and were maintained on a $12 \mathrm{hr}$ light/dark cycle (lights on 6:00 A.M. to 6:00 P.M.) in the Association For Assessment and Accreditation of Laboratory Animal Care-approved animal care facility. All experimental procedures were approved by the Institutional Animal Care and Use Committee, The University of Iowa.

Experimental objectives. The goal of the present experiments was to evaluate the role of the cloned KOR in peripheral somatic (hindpaw) and visceral (colon) tissues using antisense ODN-mediated receptor knockdown. Rats received antisense or mismatch ODNs targeting the cloned KOR or saline intrathecally for $4 \mathrm{~d}$. The antinociceptive effects of $\kappa^{-}, \mu-$, and $\delta$-ORAs, administered peripherally, were tested in the formalin test. After testing the peripheral actions of $\kappa$-OR As in antisense and mismatch ODN-treated rats in the formalin test, electrophysiological evaluation of a $\kappa$-ORA in visceral nociception was tested in the same rats. To verify whether the ODNs caused a decrease in KOR expression in the dorsal root ganglia, Western blot analysis was performed. In a separate group of animals, the recovery of antinociceptive actions of $\kappa$-ORAs 6 and $10 \mathrm{~d}$ after the termination of antisense ODN treatment was also assessed in the formalin test. The experimental strategy is diagrammed in Figure 1.

Synthesis and administration of ODNs. Antisense and mismatch ODNs 


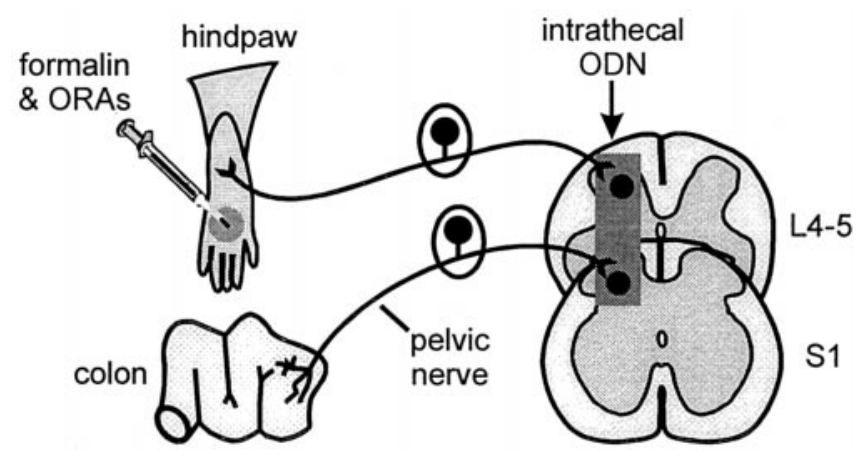

Figure 1. Diagram illustrating the experimental strategy to study the effects of KOR knock-down using antisense ODNs. Antisense ODN targeting the cloned rat KOR was administered intrathecally into the lumbosacral area twice daily (dosing interval 10-12 hr) for 4 consecutive days, each dose containing $12.5 \mu \mathrm{g}$ of ODN in a $5 \mu \mathrm{l}$ volume followed by a $10 \mu \mathrm{l}$ saline flush. The efficacy of the antisense ODN treatment to cause a knock-down of the peripheral KOR was evaluated using the formalin test. Rats showing a block of the peripheral analgesic actions of the $\kappa$-ORAs in the formalin test were subsequently examined electrophysiologically to test $\kappa$-OR A modulation of visceral nociception.

having a phosphodiester backbone, derived from the $5^{\prime}$ end of the coding sequence of the cloned rat KOR (nucleotides 6-25), were synthesized by Integrated DNA Technologies (Iowa City, IA) and reconstituted in sterile deionized water before use. Phosphodiester ODNs have been shown to be stable in CSF and devoid of many nonspecific effects associated with phosphothiorate ODNs (Wahlestedt, 1994) and hence are preferred for intrathecal administration. The sequences of the two ODNs used in these experiments were as follows: 5'-GGAAAATCTG GATGGGGGAC3' (antisense) and 5'-GGAAATACTG GTAGGGGAGC-3'(mismatch). The sequences were selected to ensure that their cross-hybridization with $\delta$ - and $\mu$-opioid receptors was minimal.

Rats were deeply anesthetized with an intraperitoneal injection of sodium pentobarbital $(45 \mathrm{mg} / \mathrm{kg}$, Nembutal; Abbott Laboratories, Abbott Park, IL) and a catheter $(8.5 \mathrm{~cm} ; \mathrm{PE}-10)$ was passed to the lumbosacral intrathecal space through an incision in the dura over the atlantooccipital joint. Animals were allowed at least $3 \mathrm{~d}$ to recover from surgery before testing. Antisense or mismatch ODNs were injected intrathecally twice daily (dosing interval 10-12 hr) for 4 consecutive days, each dose of ODN containing $12.5 \mu \mathrm{g}$ in a $5 \mu \mathrm{l}$ volume followed by a $10 \mu \mathrm{l}$ saline flush.

Behavioral study. The formalin test was performed on antisense and mismatch ODN-treated and saline-treated rats on the morning of the fifth day, $\sim 12 \mathrm{hr}$ after the last intrathecal injection of ODN or saline. Different groups of rats $(n=5-10)$ received $100 \mathrm{nmol}$ in $5 \mu$ l of selective $\kappa$ - (EMD 61,753 and $U$ 69,593), $\mu$ - (DAMGO), or $\delta$ - (deltorphin) opioid agonists or saline, injected subcutaneously into the dorsum of the right hindpaw, 10 min before formalin injection $(50 \mu \mathrm{l}, 2.5 \%$, s.c. $)$. Rats were then placed in observation chambers and observed for paw-flinching behavior. Flinching of the injected paw is a consistent component of formalin-induced behavior and has been advocated as a more robust parameter, when compared to paw licking, and less contaminated by other non-nociceptive behavioral changes (Tjolsen et al., 1992). Flinches were counted in bins of $5 \mathrm{~min}$ each, starting with the formalin injection and continuing for $50 \mathrm{~min}$. The flinch response was divided into first and second phases by summing the total number of flinches occurring between 0 and 15 and between 15 and $50 \mathrm{~min}$, respectively. In some experiments, the selective $\kappa$-opioid receptor antagonist nor-BNI $(50 \mathrm{nmol}$ in $5 \mu \mathrm{l})$ was injected into the hindpaw simultaneously with EMD 61,753. Recovery of antinociceptive actions of EMD 61,753 was also assessed in a separate group of animals 6 and $10 \mathrm{~d}$ after the termination of antisense ODN treatment.

Electrophysiological study. The experimental procedures for recording responses of pelvic nerve afferent fibers to noxious colorectal distension have been described in detail (Sengupta et al., 1996; Su et al., 1997b) and are only briefly summarized here. Rats treated with either antisense or mismatch ODN and previously tested with formalin were anesthetized with sodium pentobarbital (Nembutal) and mechanically ventilated with room air. A femoral artery and vein were catheterized for measurement of arterial pressure and administration of pentobarbital, respectively. The left carotid artery was catheterized for subsequent drug administration. Core body temperature was maintained at $37^{\circ} \mathrm{C}$. The lower abdomen was exposed by a 3- to 4-cm-long incision laterally at the left flank. A flaccid, flexible latex balloon $6-$ to $7-\mathrm{cm}$-long and $2-3 \mathrm{~cm}$ in diameter was inserted intra-anally into the descending colon and rectum. The balloon catheter was connected to a distension control device via a low-volume pressure transducer, and the colon was distended with air. The left pelvic nerve was isolated from the surrounding fatty tissues, and a pair of Teflon-coated stainless steel wires that were stripped at the tips were wrapped around the pelvic nerve and sealed with a nonreactive silicon gel (Wacker Silicone Corporation, Adrian, MI). The hypogastric, pudendal, and femoral nerves were isolated and transected. The sciatic nerve was approached through the ischiatic notch and transected.

The lumbosacral spinal cord was exposed by laminectomy (T13-S1), and the rat was suspended from thoracic vertebral and ischia clamps. The dorsal skin was reflected laterally and tied to make a pool for mineral oil. The dura membrane was carefully removed, and the spinal cord was covered with warm $\left(37^{\circ} \mathrm{C}\right)$ mineral oil. The S1 dorsal root was decentralized close to its entry to the spinal cord. Recordings of single units (from a fine filament of the dorsal root) were made from the distal cut end of the central process of the S1 dorsal root, $\sim 3 \mathrm{hr}$ after the conclusion of formalin testing. Action potentials, monitored continuously by analog delay, were processed through a window discriminator, and the frequency of impulses was counted using the Spike2/CED 1401 program.

Pelvic nerve input to the $\mathrm{S} 1$ dorsal root was identified first by electrical stimulation of the pelvic nerve (one $0.5 \mathrm{msec}$ square wave pulse at $3-8 \mathrm{~V}$ ). If a fiber responded to distension, the effect of $\kappa$-OR A EMD 61,753 given intra-arterially was tested on responses to noxious distension $(80 \mathrm{mmHg}$, $30 \mathrm{sec}$ ) of the colon. Each dose of the drug was administered 2 min before the onset of distension. Dose-response relationships in antisense and mismatch ODN-treated rats were obtained by giving cumulative doses of EMD $61,753(0.5,1,2,4,8,16$, and $32 \mathrm{mg} / \mathrm{kg}$; doses administered at 4.5 min intervals).

Drugs. EMD 61,753 (MW: 469.1, a gift from Dr. Andrew Barber; E. Merck, Darmstadt, Germany) was dissolved in 10\% DMSO. DAMGO (MW: 523.7; Sigma, St. Louis, MO) and nor-BN I dihydrochloride (MW: 734.7; Research Biochemicals, Natick, MA) were dissolved in saline. U 69,593 (MW: 521.5; Sigma) was dissolved in ethanol and [D-Ala ${ }^{2}$ ] deltorphin (MW: 782.89; Research Biochemicals) was dissolved in 100\% DMSO. The lack of effects of DMSO, ethanol, and saline were determined in preliminary experiments.

Western blot analysis. In a separate group of saline, antisense, or mismatch ODN-treated animals, Western blot analysis was performed to assess KOR expression levels in L4, L5, L6, and S1 dorsal root ganglia (DRG). Tissue homogenates were prepared in a phosphate lysis buffer (10 $\mathrm{mm}$ Tris, $1 \%$ Triton X-100, $5 \mathrm{~mm} \mathrm{Na}{ }_{2}$ EDTA, $50 \mathrm{~mm} \mathrm{NaCl}, 30 \mathrm{~mm}$ sodium pyrophosphate, $50 \mathrm{~mm}$ sodium orthovanadate, $0.5 \%$ sodium deoxycholate, and $50 \mu \mathrm{g} / \mathrm{ml}$ PMSF) from DRG of rats $12 \mathrm{hr}$ after the last bolus injection of either ODNs or saline. Soluble extracts were resolved by SDS-PAGE and transferred to polyvinylidene fluoride (Millipore, Bedford, MA). Immunoblots were blocked overnight with $5 \%$ milk in Tris-buffered saline (TBS) at $4^{\circ} \mathrm{C}$ and then incubated overnight at $4^{\circ} \mathrm{C}$ with an affinity-purified antibody raised against an internal region of the cloned rat KOR (PharMingen KA8) diluted 1:1000 in 5\% milk and TBS. Immunoblots were then incubated for $2 \mathrm{hr}$ at room temperature with anti-rabbit IgG-HRP secondary antibody (Santa Cruz Biotechnology, Santa Cruz, CA; SC-2004) diluted 1:5000 in 5\% milk and TBS. Immunoreactive proteins were visualized with enhanced chemiluminescence (Amersham, Arlington Heights, IL; NA934).

Data analysis. All experimental groups in the behavioral study consisted of at least five animals, and data are presented as mean \pm SEM. The data were analyzed by one-way ANOVA with Tukey's test for post hoc comparisons. A value of $p<0.05$ was considered statistically significant in all tests.

\section{RESULTS}

\section{Effects of selective ORAs on formalin-produced flinching in KOR antisense ODN-treated rats}

Injection of formalin into the dorsal surface of the hindpaw produced characteristic biphasic flinching behavior with clear first $(0-15 \mathrm{~min})$ and second (15-50 min) phases (Figs. $2 A, 3 A, 4 A, 5 A)$. On average, rats that received pretreatment with saline $(10 \mathrm{~min}$ before formalin) flinched a total of $345 \pm 20$ times between 15 and $50 \mathrm{~min}$ after formalin. Pretreatment with $100 \mathrm{nmoles}$ of selective $\kappa$ (EMD 61,753 and U 69,593), $\mu$ - (DAMGO), or $\delta$ - (deltorphin) ORAs significantly decreased the number of second phase flinches after their administration, $10 \mathrm{~min}$ before formalin at the same site (Figs. $2 B, 3 B, 4 B$ ). The first phase of the response to formalin was not significantly altered by pretreatment with the ORAs tested. The second phase antinociceptive actions of the two $\kappa$-ORAs tested were significantly blocked by intrathecal treatment with KOR antisense, but not mismatch ODN treatment (Figs. $2 B, 3 B$ ). In contrast, neither KOR antisense nor mismatch ODN treatment had any effect on the antinociceptive actions of either DAMGO or deltorphin (Fig. 4). Additionally, administration of KOR antisense ODN alone had no effect on formalin-induced flinching behavior (Figs. $2 B, 3 B, 4 B$ ). The antinociceptive action of EMD 61,753 was also blocked by the $\kappa$-opioid receptor-selective antagonist nor-BNI (50 nmoles, injected simultaneously with EMD 61,753), thus demonstrating that peripheral agonist effects were selective for KOR (Fig. 2B). 


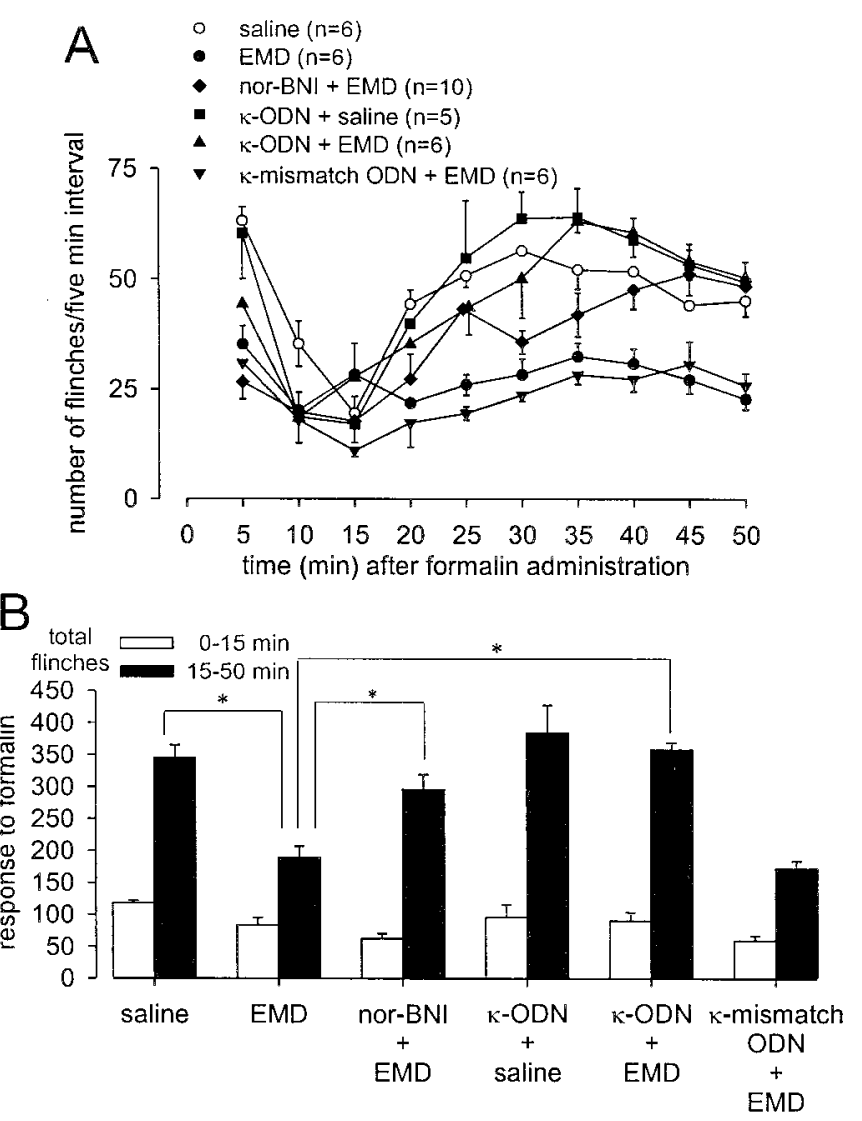

Figure 2. Effect of $\kappa$-ODN treatment on peripheral EMD 61,753 analgesia in the formalin flinch test. Formalin $(50 \mu \mathrm{l}, 2.5 \%)$ was injected into the dorsal surface of the rat hindpaw 10 min after the injection of drugs or saline at the same site. $A$, Time course of formalin-induced flinching behavior for the different treatment groups exhibits a characteristic biphasic response. Data are summarized in $B$. One hundred nanomoles of the $\kappa$-ORA EMD 61,753 (EMD) significantly blocked the formalin-induced second phase flinching response (an asterisk indicates a $p$ value of $<0.05$ ). The antinociceptive effects of EMD were blocked by KOR antisense, but not mismatch ODN treatment. Fifty nanomoles of the $\kappa$-opioid receptor antagonist nor-BNI injected simultaneously with EMD antagonized the antinociceptive actions of EMD. Administration of $\kappa$-ODN alone did not affect the formalin response.

To verify that the blockade of antinociceptive actions of $\kappa$-ORAs is not attributable to a generalized neurotoxicity brought about by antisense ODN administration, effects of EMD 61,753 were assessed in the formalin test 6 and $10 \mathrm{~d}$ after the termination of antisense ODN treatment. A partial recovery of the antinociceptive actions of EMD 61,753 was seen $6 \mathrm{~d}$ after the last antisense ODN injection, and a complete recovery was observed after $10 \mathrm{~d}$ (Fig. 5).

\section{Effects of EMD 61,753 on responses of pelvic nerve afferent fibers to noxious colonic distension}

Electrophysiological evaluation of $\kappa$-ORA modulation of pelvic nerve afferent fiber responses to colonic distension was performed in mismatch and antisense ODN-treated rats after the formalin test. Recordings were made from a total of 14 pelvic nerve sensory fibers in the decentralized S1 dorsal root. In contrast to the observations in the formalin test, in which the antinociceptive actions of the $\kappa$-ORA EMD 61,753 were blocked by KOR antisense ODN treatment, EMD 61,753 dose-dependently attenuated the responses of pelvic nerve afferent fibers to noxious colonic distension $(80 \mathrm{mmHg})$ in both KOR antisense and mismatch ODN-treated rats (Fig. 6). The estimated $\mathrm{ED}_{50}$ values (dose-attenuating response magnitude to $50 \%$ of control) and $95 \%$ confidence intervals for EMD 61,753 in antisense $(7 \mathrm{mg} / \mathrm{kg} ; 1.7-12.4 \mathrm{mg} / \mathrm{kg}$ ) and mismatch $(6 \mathrm{mg} / \mathrm{kg} ; 0.6-11.37 \mathrm{mg} / \mathrm{kg})$ ODN-treated rats did not

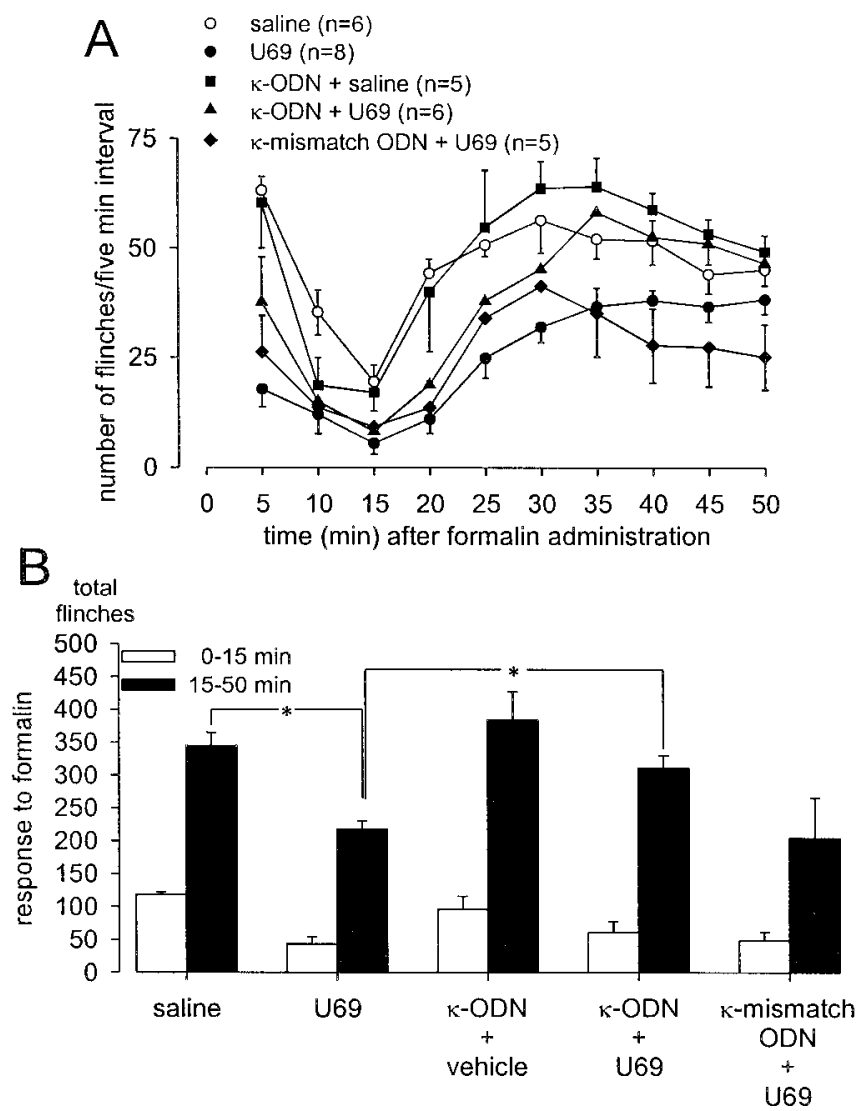

Figure 3. Effect of $\kappa-\mathrm{ODN}$ treatment on peripheral U 69,593 analgesia in the formalin flinch test. Formalin $(50 \mu \mathrm{l}, 2.5 \%)$ was injected into the dorsal surface of the rat hindpaw 10 min after the injection of drug or saline at the same site. $A$, Time course of formalin-induced flinching behavior for the different treatment groups exhibits a characteristic biphasic response. Data are summarized in $B$. One hundred nanomoles of the $\kappa$-ORA U 69,593 (U69) significantly blocked the formalin-induced second phase flinching response. The antinociceptive effects of U69 were blocked by KOR antisense, but not mismatch ODN treatment. Administration of $\kappa$-ODN alone did not affect the formalin response. ${ }^{*} p<0.05$.

differ from each other or from the $\mathrm{ED}_{50}$ of EMD 61,753 determined in other experiments (7.9 mg/kg; Sengupta et al., 1999).

\section{Effects of ODN treatment on KOR protein levels in rat DRG}

Western blot analysis was performed to compare KOR protein content in L4, L5, L6, and S1 DRGs of rats treated with saline, antisense ODN, or mismatch ODN. Immunoblots of tissue extracts showed immunoreactive proteins at molecular masses of $\sim 43$ and $70 \mathrm{kDa}$ in the DRG of saline-treated control animals (Fig. 7, lanes labeled $C$ ). The KOR 1 cDNA clone predicts a protein with a molecular mass of $\sim 43 \mathrm{kDa}$ (Arvidsson et al., 1995). The protein detected at $70 \mathrm{kDa}$ most likely corresponds to a posttranslationally modified form of the KOR. A clear downregulation of KOR protein was observed in antisense ODN-treated (Fig. 7, lanes labeled $A S$ ) but not in mismatch ODN-treated animals (Fig. 7, lanes labeled $M M$ ).

\section{DISCUSSION}

The present experiments support the hypothesis that there exists in the colon a novel site at which $\kappa$-ORAs significantly attenuate visceral nociception. Intrathecal administration of antisense, but not mismatch ODNs to the cloned KOR blocked the antinociceptive effects of $\kappa$-ORAs injected into the paw without affecting the actions of DAMGO ( $\mu$-ORA) or deltorphin ( $\delta$-ORA). Significantly, the ability of the $\kappa$-OR A EMD 61,753 to dose-dependently attenuate responses of pelvic nerve afferent fibers to colonic distension was unaffected by the same ODN treatment. We used 

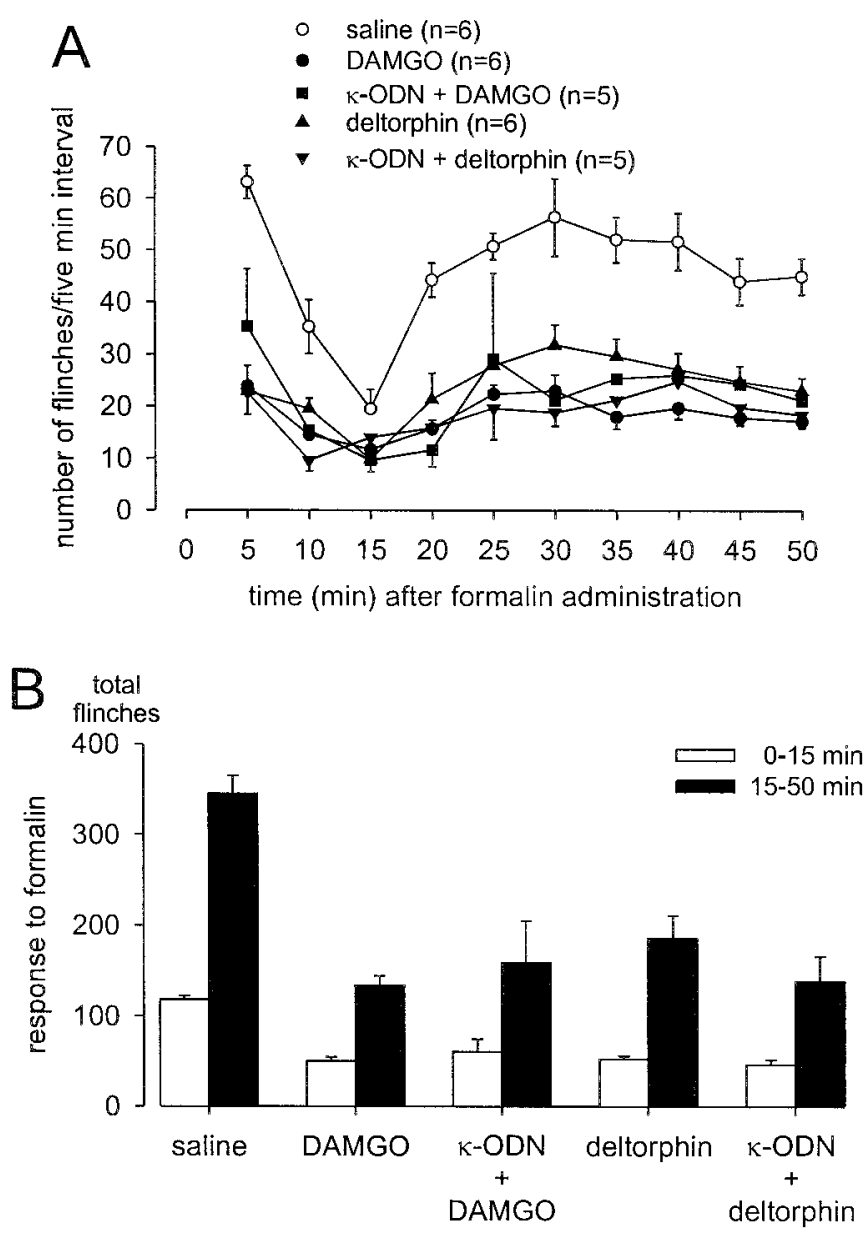

Figure 4. Effects of $\kappa-\mathrm{ODN}$ treatment on peripheral antinociceptive actions of $\mu$-ORA (DAMGO) and $\delta$-ORA (deltorphin) in the formalin flinch test. One hundred nanomoles of drug were administered $10 \mathrm{~min}$ before formalin in the dorsal surface of the rat hindpaw. $A$ illustrates the time course of the formalin-induced flinching response; the data are summarized in $B$. Both DAMGO and deltorphin significantly attenuated the second phase flinching response $(p<0.05)$. Administration of KOR antisense ODN had no effect on the antinociceptive actions of either of these two drugs.

Western blot analysis to verify that intrathecal ODN administration causes a KOR protein knock-down in the L4-S1 DRG.

\section{Antisense strategies in opioid pharmacology}

Antisense ODNs have been extensively used to correlate the pharmacology and molecular biology of opioid receptors (Pasternak and Standifer, 1995; Hutcheson et al., 1999). The turnover rate of opioid receptors is $\sim 4 \mathrm{~d}$ in vivo (Pasternak, 1993), which necessitated administration of the KOR antisense ODN for $4 \mathrm{~d}$ so that not only new protein synthesis was blocked, but also the pre-existing protein was cycled out.

Antisense ODNs targeting the KOR have been shown to selectively inhibit $\kappa$-ORA antinociception in rats (Adams et al., 1994) and, more recently, to cause hypertension after injection into the hippocampus (Wright et al., 1999). Intrathecal administration of antisense ODNs has also been demonstrated to cause a knockdown of peripheral proteins. For example, intrathecal administration of antisense ODN targeting the $\mu$-opioid receptor significantly decreased peripheral DAMGO-produced inhibition of prostaglandin E2 hyperalgesia and also DAMGO-induced inhibition of voltage-gated $\mathrm{Ca}^{2+}$ currents in cultured rat DRG neurons (Khasar et al., 1996). Intrathecal administration of $\delta$-opioid receptor (DOR) ODN selectively blocks the antinociceptive effects of peripherally administered $\delta$-ORAs (Bilsky et al., 1996). Radioligand binding experiments in the same study indicated an $\sim 50 \%$ de-

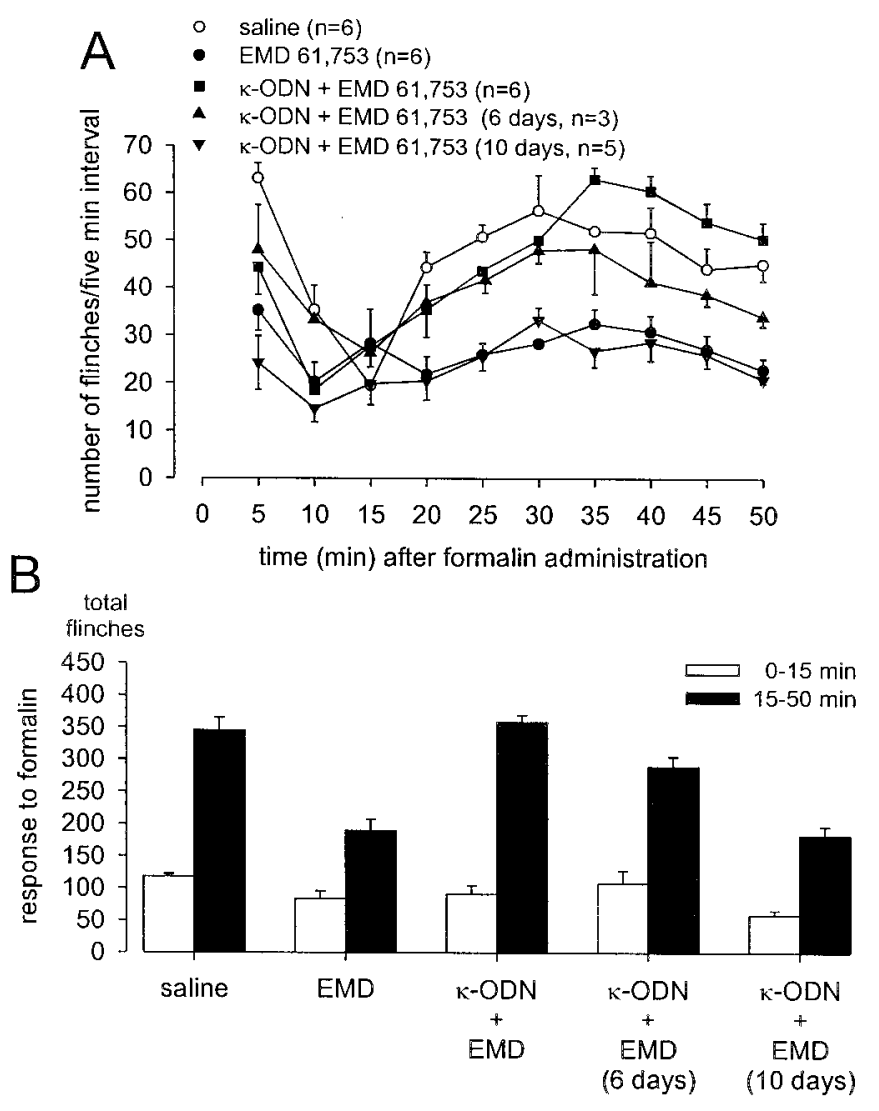

Figure 5. Recovery of antinociceptive actions of $\kappa$-ORAs 6 and $10 \mathrm{~d}$ after the termination of KOR antisense ODN treatment. One hundred nanomoles of the $\kappa$-OR A EMD 61,753 (EMD) was administered 10 min before formalin in the dorsal surface of the rat hindpaw in all cases. $A$, Time course of formalin-induced flinching behavior; the data are summarized in $B$. Administration of $\kappa$-ODN significantly blocked the antinociceptive actions of EMD $(p<0.05)$. A partial recovery of antinociceptive actions of EMD was seen $6 \mathrm{~d}$ after the termination of $\kappa$-ODN treatment, and a complete recovery was observed after $10 \mathrm{~d}$.

crease in $\delta$-opioid receptors in the lumbar spinal cord. A large proportion of $\delta$-opioid receptors in rat spinal cord are located on primary afferent nerve terminals (Dado et al., 1993), suggesting that one of the sites of action of intrathecally administered DOR antisense ODN is the DRG, where the opioid receptors are synthesized and subsequently transported to central and peripheral terminals. Likewise, we verified using Western blot analysis that lumbosacral intrathecal administration of antisense ODNs directed toward the cloned KOR causes a KOR knock-down in the L4-S1 DRG. Although the KOR downregulation we observed was almost complete, it is possible that the antibody could not detect some KOR protein that persisted in DRG after the antisense ODN treatment. We have also behaviorally demonstrated the efficacy of the antisense ODN, which selectively blocked the antinociceptive actions of peripherally administered $\kappa$-ORAs in the formalin test, an effect not produced by administration of mismatch ODN. Moreover, the antisense ODN was selective in its effect; the efficacy of the $\mu$ - and $\delta$-ORAs in the formalin test was not affected.

\section{Role of $\kappa$-ORAs in modulating visceral nociception}

Whereas $\kappa$-ORAs are well documented to be antinociceptive in cutaneous models of pain (Leighton et al., 1988; Herraro and Headley, 1993), several recent studies point toward a significant role in modulating visceral pain. The role of the KOR gene product in the perception of visceral chemosensitivity has been demonstrated in KOR-deficient mice, which have a decreased threshold to a noxious visceral chemical stimulus when compared to their wildtype littermates (Simonin et al., 1998). A peripheral site of action of $\kappa$-ORAs in the viscera has been recently documented in reports 


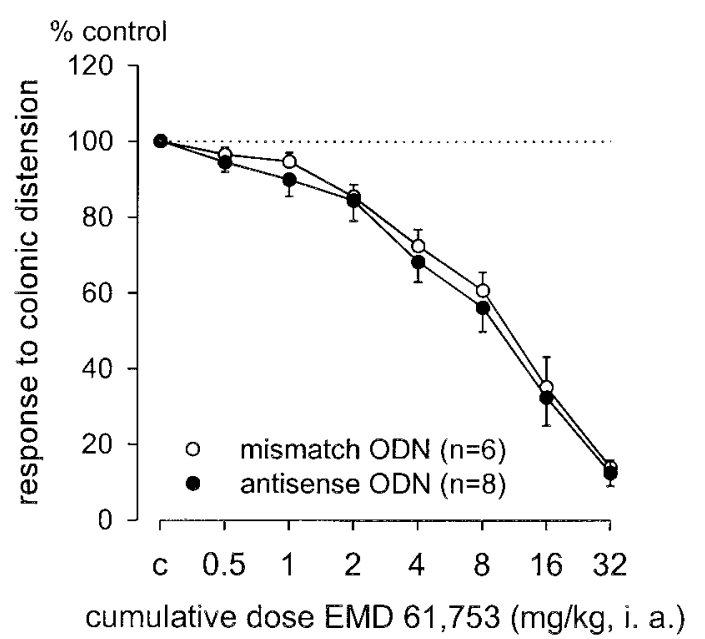

Figure 6. Effect of KOR antisense and mismatch ODN treatment on EMD 61,753 modulation of visceral nociception. ODN-treated rats, previously tested with formalin, were deeply anesthetized and were examined electrophysiologically. EMD 61,753 dose-dependently inhibited the responses of the pelvic nerve afferent fibers to noxious colonic distension $(80 \mathrm{mmHg}, 30$ $\mathrm{sec})$. There were no differences in effects of the drug in antisense or mismatch ODN-treated rats.

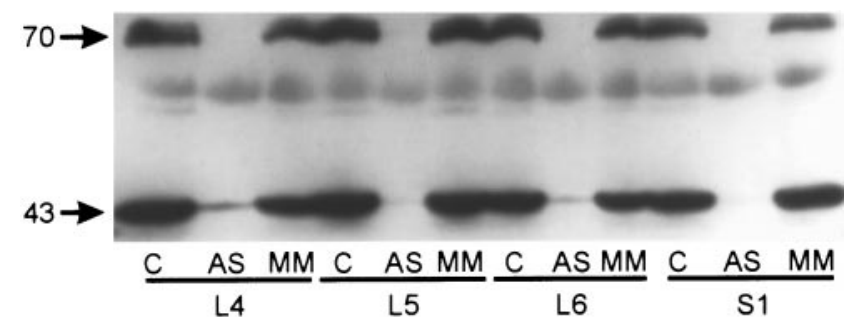

Figure 7. Immunoblot showing the effects of ODN treatment on KOR protein levels in rat DRG. Tissue extracts were prepared from L4, L5, L6, and S1 DRG of saline $(C)$, antisense ODN-treated $(A S)$, and mismatch ODN-treated $(M M)$ rats. Samples were normalized for protein content using BCA quantification. Each lane was loaded with $\sim 100 \mu \mathrm{g}$ of protein, and immunoreactive bands were revealed at 43 and $70 \mathrm{kDa}$ with an antibody directed against an internal region of the cloned rat KOR. Antisense ODN, but not mismatch ODN treatment, caused a clear downregulation of KOR protein at all the DRGs examined. Similar results were obtained from duplicate experiments.

in which $\kappa$-ORAs, but not $\mu$ - or $\delta$-ORAs, dose-dependently inhibited responses of mechanosensitive pelvic nerve afferent fibers innervating the urinary bladder or colon (Sengupta et al., 1996; Su et al., 1997a,b). Interestingly, naloxone at non-receptor-selective doses was able to partially antagonize the effects of the $\kappa$-ORAs tested, but the KOR-selective antagonists nor-BNI and DIPPA were without effect (Su et al., 1997a). Additionally, the $\mathrm{ED}_{50}$ values for the receptor-selective $\kappa$-OR As examined were virtually identical, ranging between 2 and $10 \mathrm{mg} / \mathrm{kg}$ (Su et al., 1997b), which is in contrast to the broad range of antinociceptive doses reported in the literature for these same $\kappa$-ORAs (Chang et al., 1984; Devlin and Shoemaker, 1990; Nock et al., 1990; Paul et al., 1990). This led us to hypothesize that $\kappa$-ORAs mediate their antinociceptive actions in the viscera by acting at a $\kappa$-opioid-like receptor unlike the KOR cloned and characterized from the CNS or any opioid receptor subtype documented in the literature. Consistent with this hypothesis, the $\kappa$-ORA EMD 61,753 in the present study was observed to dose-dependently inhibit responses of pelvic nerve afferent fibers to noxious colonic distension in antisense-ODN treated rats in which a knock-down of the cloned KOR is demonstrated.

\section{Visceral $\boldsymbol{\kappa}$-opioid agonist site of action}

The present results, combined with our previous electrophysiological data, suggest that $\kappa$-ORAs attenuate responses to noxious colonic distension by acting at a receptor that is distinct from the KOR cloned in the CNS. The present experiments neither document nor localize such a receptor. An immunohistochemical study using antibodies raised to the cloned KOR demonstrated that $\kappa$-opioid receptors, although not present in the smooth muscle cells in the rat colon, were present on myenteric and submucosal plexus neurons as well as on interstitial cells of Cajal (Bagnol et al., 1997). At present, there is no evidence for the existence of any opioid receptor associated with the peripheral endings of pelvic nerve sensory fibers. Accordingly, it is possible that $\kappa$-ORA effects on pelvic nerve sensory fibers arise indirectly through action at the $\kappa$-opioid receptor associated with neurons of the intrinsic nervous system of the gut. Intrinsic and extrinsic primary afferent nerve terminals, however, are not anatomically organized in a manner that would make such an interaction likely. That is, intrinsic primary afferent nerve terminals are not "presynaptic" to terminals of extrinsic neurons. Intrinsic primary afferent neurons have been shown to interact with each other and with second order neurons (interneurons and motor neurons) of the enteric nervous system, but not with extrinsic primary afferent neurons such as studied here (Furness et al., 1998).

The existence of KOR 1 splice variants has been suggested in a recent report (Pasternak et al., 1999). In this study, the analgesic actions of $\alpha$-neoendorphin and dynorphin B in mice were antagonized by nor-BNI but not blocked by antisense ODN targeting exon 1 of the KOR. Although we find nor-BNI to be without effect in our electrophysiology studies, we cannot rule out the possibility that $\kappa$-ORA effects in the viscera are mediated by a splice variant encoded by the KOR 1 gene. Such a splice variant would neither be affected by the present antisense ODN treatment nor be recognized by the antibody used in the Western blot analysis. Further studies using antisense ODN sequences targeting other regions of the cloned KOR mRNA would therefore be informative, although an antibody that can be used to assess the differential knock-down of various KOR 1 splice variants is not currently available. Alternately, the receptor in the viscera may be heterodimeric. A recent report (Jordan and Devi, 1999) demonstrated the ability of $\kappa$ - and $\delta$-opioid receptors to form a heterodimeric receptor with altered ligand binding and functional properties. However, the inability of $\delta$-ORAs to modulate the responses of mechanosensitive pelvic nerve afferent fibers innervating the colon (Sengupta et al., 1996) and the comparable efficacy of subtype-selective $\kappa$-ORAs ( $\mathrm{Su}$ et al., 1997b) makes us believe that the presently investigated visceral receptor does not represent such a $\kappa-\delta$ heterodimer. We have previously eliminated the possibility that this novel receptor may be an orphan receptor like ORL 1 at which the endogenous orphanin FQ/nociceptin peptide acts (Meunier et al., 1995; Reinscheid et al., 1995) because nociceptin had no effect on pelvic nerve afferent fibers to colorectal distension (V. Julia and G. F. Gebhart, unpublished observations). It remains to be tested whether this novel receptor maybe an opioid-somatostatin-like receptor. Two novel, related genes, named GPR7 and GPR8, have been described which encode receptors with structural features in common with both opioid and somatostatin receptors and also bind several opioid drugs (O'Dowd et al., 1995). Finally, several $\kappa$-ORAs, in addition to their opioid effects, have been demonstrated to possess $\mathrm{Na}^{+}$ channel blocking properties (Wong et al., 1990; Pugsley et al., 1993). Although $\kappa$-ORAs have no effect on conduction velocity or amplitude of action potentials of pelvic nerve afferent fibers (Sengupta et al., 1996; Su et al., 1997a,b), and $\kappa$-ORA effects are partially reversed by naloxone, we cannot completely rule out the possibility that $\kappa$-ORA actions are mediated by $\mathrm{Na}^{+}$channel blockade.

In summary, the present experiments provide further evidence for the existence of a novel, peripheral $\kappa$-opioid-like receptor localized in the colon. Agonists directed toward this receptor are attractive targets as analgesics, potentially free of the undesirable side effects associated with activation of central $\kappa$-opioid receptors and could provide relief for visceral pain states like inflammatory 
bowel disease, for which satisfactory treatment is not currently available.

\section{REFERENCES}

Adams JU, Chen X, DeRiel JK, Adler MW, Liu-Chen LY (1994) Intracerebroventricular treatment with an antisense oligonucleotide to a kappa opioid receptor, inhibited kappa-agonist induced analgesia in rats. Brain Res 667:129-132.

Arvidsson U, Riedl M, Chakrabarti S, Vulchanova L, Lee JH, Nakano AH, Lin X, Loh HH, Law PY, Wessendorf MW, Elde R (1995) The $\kappa$-opioid receptor is primarily postsynaptic: combined immunohistochemical localization of the receptor and endogenous opioids. Proc Natl Acad Sci USA 92:5062-5066.

Bagnol D, Mansour A, Akil H, Watson SJ (1997) Cellular localization and distribution of the cloned mu and kappa opioid receptors in the gastrointestinal tract. Neuroscience 81:579-591.

Bilsky EJ, Wang T, Lai J, Porreca F (1996) Selective blockade of peripheral delta opioid agonist induced antinociception by intrathecal administration of delta receptor antisense oligodeoxynucleotide. Neurosci Lett 220:155-158.

Burton MB, Gebhart GF (1998) Effects of kappa-opioid receptor agonists on responses to colorectal distension in rats with and without acute colonic inflammation. J Pharmacol Exp Ther 285:707-715.

Chang KJ, Blanchard SG, Cuatrecasas P (1984) Benzomorphan sites are ligand recognition sites of putatative epsilon-receptors. Mol Pharmacol $26: 484-488$

Clark JA, Liu L, Price M, Hersh B, Edelson M, Pasternak GW (1989) Kappa opiate receptor multiplicity: evidence for two U50-488-sensitive $\kappa_{1}$ subtypes and novel $\kappa_{3}$ subtype. J Pharmacol Exp Ther 251:461-468.

Dado RJ, Law PY, Loh HH, Elde R (1993) Immunofluorescent identification of a delta (delta)-opioid receptor on primary afferent nerve terminals. NeuroReport 5:341-344.

Devlin T, Shoemaker WJ (1990) Characterization of kappa opioid binding using dynorphin A1-13 and U69,593 in the rat brain. J Pharmacol Exp Ther 253:749-759.

Furness JB, Kunze WAA, Bertrand PP, Clerc N, Bornstein JC (1998) Intrinsic primary afferent neurons of the intestine. Prog Neurobio 54:1-18.

Herraro JF, Headley PM (1993) Functional evidence for multiple receptor activation by $\kappa$-ligands in the inhibition of spinal nociceptive reflexes in the rat. Br J Pharmacol 110:303-309.

Hutcheson DM, Sanchez-Blazques P, Rodriquez-Diaz M, Garzon J, Schmidhammer H, Borsodi A, Roques BP, Maldonado R (1999) Use of selective antagonists and antisense oligonucleotides to evaluate the mechanisms of BUBU antinociception. Eur J Pharmacol 383:29-37.

Jordan BA, Devi LA (1999) G-protein-coupled receptor heterodimerization modulates receptor function. Nature 399:697-700.

Joshi SK, Su X, Gebhart GF (1999) Further evidence for the existence of a novel, peripheral kappa-opioid-like receptor localized in the colon. Soc Neurosci Abstr 25:925.

Khasar SG, Gold MS, Dastmalchi S, Levine JD (1996) Selective attenuation of mu-opioid receptor-mediated effects in rat sensory neurons by intrathecal administration of antisense oligodeoxynucleotides. Neurosci Lett 218:17-20.

Kolesnikov Y, Jain S, Wilson R, Pasternak GW (1996) Peripheral $\kappa_{1}$ opioid receptor-mediated analgesia in mice. Eur $\mathrm{J}$ Pharmacol 310:141-143.

Leighton GE, Rodriguez RE, Hill RG, Hughes J (1988) $\kappa$-Opioid agonists produce antinociception after i.v. and i.c.v. but not intrathecal administration in the rat. Br J Pharmacol 93:553-560.

Meunier J-C, Mollereau C, Toll L, Suaudeau C, Moisand C, Alvinerie P, Butour JL, Guillemot JC, Ferrara P, Monsarrat B, Mazarguil H, Vassart G, Parmentier M, Costentin J (1995) Isolation and structure of the endogenous agonist of opioid receptor-like ORL 1 receptor. Nature 337:532-535.
Minami M, Toya T, Katao Y, Maekawa K, Nakamura S, Onogi T, Kaneko S, Satoh M (1993) Cloning and expression of a cDNA for the rat kappa-opioid receptor. FEBS Lett 329:291-295.

Nock B, Giordano AL, Cicero TJ, O'Connor LH (1990) Affinity of drugs and peptides for U69,593-sensitive and -insensitive kappa opiate binding sites: the U69,593-insensitive site appears to be the beta endorphinspecific epsilon receptor. J Pharmacol Exp Ther 254:412-419.

O'Dowd BF, Scheideler MA, Nguyen T, Cheng R, Rasmussen JS, Marchese A, Zastawny R, Heng HQ, Tsui L-C, Shi X, Asa S, Puy L, George SR (1995) The cloning and chromosomal mapping of two novel human opioid somatostatin like receptor genes, GPR7 and GPR8, expressed in discrete areas of the brain. Genomics 28:84-91.

Pasternak GW (1993) Pharmacological mechanisms of opioid analgesics. Clin Neuropharmacol 16:1-18.

Pasternak GW, Standifer KM (1995) Mapping of opioid receptors using antisense oligodeoxynucleotides: correlating their molecular biology and pharmacology. Trends Pharmacol Sci 16:344-350.

Pasternak KR, Rossi GC, Zuckerman A, Pasternak GW (1999) Antisense mapping KOR-1: evidence for multiple kappa analgesic mechanisms. Brain Res 826:289-292.

Paul D, Levison JA, Howard DH, Pick CG, Hahn EF, Pasternak GW (1990) Naloxone benzoylhydrazone (NalBzoH) analgesia. J Pharmacol Exp Ther 255:769-774.

Pugsley MK, Saint DA, Penz W P, Walker MJ (1993) Electrophysiological basis for the antiarrhythmic actions of the $\kappa$ agonist PD129290 and its RR(+)-enantiomer PD129289. Br J Pharmacol 110:1579-1585.

Reinscheid RK, Nothacker HP, Bourson A, Ardati A, Henningsen RA, Bunzow JR, Grandy DK, Lengen H, Monsma Jr FJ, Civelli O (1995) Orphanin FQ: a neuropeptide that activates an opioid like G proteincoupled receptor. Science 270:792-794.

Sengupta JN, Su X, Gebhart GF (1996) Kappa, but not mu or delta opioids attenuate responses to distension of pelvic nerve afferents innervating the colon of the rat. Gastroenterology 111:968-980.

Sengupta JN, Snider A, Su X, Gebhart GF (1999) Effects of kappa opioids in the inflamed rat colon. Pain 79:175-185.

Simonin F, Valverde O, Smadja C, Slowe S, Kitchen I, Dierich A, Meur ML, Roques BP, Maldonado R, Kieffer BL (1998) Disruption of the $\kappa$-opioid receptor gene in mice enhances sensitivity to chemical visceral pain, impairs pharmacological actions of the selective $\kappa$-agonist U-50,488H and attenuates morphine withdrawal. EMBO J 17:886-897.

Su X, Sengupta JN, Gebhart GF (1997a) Effects of opioids on mechanosensitive pelvic nerve afferent fibers innervation the urinary bladder of the rat. J Neurophysiol 77:1566-1580.

Su X, Sengupta JN, Gebhart GF (1997b) Effects of kappa opioid receptorselective agonists on responses of pelvic nerve afferents to noxious colorectal distension. J Neurophysiol 78:1003-1012.

Su X, Julia V, Gebhart GF (2000) Effects of intracolonic opioid receptor agonists on polymodal pelvic nerve afferent fibers in the rat. J Neurophysiol 83:963-970.

Tjolsen A, Berge O-C, Hunskaar S, Rosland JH, Hole K (1992) The formalin test: an evaluation of the method. Pain 51:5-17.

Wahlestedt C (1994) Antisense oligonucleotide strategies in neuropharmacology. Trends Pharmacol Sci 15:42-46.

Wong TM, Lee AY, Tai KK (1990) Effect of drugs interacting with opioid receptors during normal perfusion or ischaemia and reperfusion in the isolated heart-an attempt to identify cardiac opioid receptor subtypes involved in arrhythmogenesis. J Mol Cell Cardiol 22:1167-1175.

Wright RC, McConnaughey MM, Phan TA, Ingenito AJ (1999) $\kappa$-opioid receptor antisense oligonucleotide injected into rat hippocampus causes hypertension. Eur J Pharmacol 377:57-61.

Zukin RS, Eghbali M, Olive D, Unterwald EM, Tempel A (1988) Characterization and visualization of rat and guinea pig brain $\kappa$ opioid receptors: evidence for $\kappa_{1}$ and $\kappa_{2}$ opioid receptors. Proc Natl Acad Sci USA 85:4061-4065. 